\title{
Student Attitude to Intercultural Communication and Intercultural Interaction in Social Networks
}

\author{
Roza Sh. Akhmadieva \\ Kazan State Institute of Culture, Russia \\ ORCID: 0000-0002-1583-3975 \\ Tatyana Yu. Guryanova \\ Chuvash State University named after I.N. Ulyanov, Russia \\ ORCID: 0000-0003-3440-4479
}

Aleksey V. Kurakin

Financial University under the Government of the Russian Federation, Russia

ORCID: 0000-0003-0812-8212

Alexandr L. Makarov

Ulyanovsk State Agrarian University named after P.A. Stolypin, Russia

ORCID: 0000-0002-6696-7260

Anna I. Skorobogatova

Kazan Innovative University named after V. G. Timiryasov, Russia

ORCID: 0000-0003-1793-8161

Victoria V. Krapivina

Gzhel State University, Russia

ORCID: 0000-0002-4741-8979

\begin{abstract}
The relevance of this article is conditioned by the need to analyze and study the student views and positions on the issue of intercultural communication and intercultural interaction, as it is obvious that in the foreseeable future we will continue to live in a multiethnic, multicultural society and strive for the successful coexistence of many different cultures in social networks. The aim of the study is to identify the attitude of students communicating in social networks to ethnocentrism. The leading methods for the study of this problem are the methods of questioning and testing, allowing making a qualitative analysis of the peculiarities of the attitude of students communicating in social networks, to ethnocentrism, and allowing identifying the position of students on the issue of intercultural communication and intercultural interaction. The article reveals the criteria peculiar to the representatives of different ethnic groups with a high level of ethnocentrism. These students consider everything that happens in their culture to be natural and correct, and in others to be wrong; consider the customs of their group as universal: "what is good for us is good for others"; consider the norms, roles and values of their group to be absolutely correct; act so that the representatives of their group feel like winners; feel hostility towards external groups. It is determined that the presence of a set of these criteria and properties (or most of them) in the ethnic consciousness of the individual, allows us to talk about a high level of ethnocentrism. The novelty and originality of the study lies in the fact that a set of criteria characterizing the opinion of students, supporters of cultural relativism is revealed: they are often in contact with representatives of other ethnic groups
\end{abstract}


and nationalities in social networks; absolutely do not feel discomfort in communicating with foreign cultural representatives, on the contrary, such communication is of great interest; in the formation of any group do not give preference to representatives of their own people, and are guided by other selection criteria; do not regard the culture of their people as a role model for other Nations. A set of criteria is identified for supporters of ethnocentrism: they believe everything that happens in their culture, natural and correct and others wrong; consider the customs of their group as universal; consider the norms, roles and values of their group is certainly correct; feel hostility towards external groups; in General, are rarely in contact with the representatives of other ethnic groups and nationalities; feel discomfort in communicating with other cultures representatives; believe that the loss of identity of their ethnic group is an unambiguously negative phenomenon; they do not consider the cultures of all peoples equally important and equal.

Keywords: students, intercultural communication, intercultural interaction, ethnocentrism

\section{INTRODUCTION}

The world in which we live is multi-ethnic: many different ethnic groups and peoples coexist simultaneously in it. In today's multi-ethnic world, ethnically homogeneous countries and communities are rather a rare exception, so in our time the problems of inter-ethnic communication, inter-ethnic interaction and coexistence are becoming paramount and come to the fore both globally and locally, within one country or a certain community (Artanovsky, 1979; Birova, Vasbieva \& Masalimova, 2017; Cherdymova et al., 2019a, 2019b; Drobizheva, 2001; Novikova et al., 2018; Roshchin, 2014; Ulybina, 2015; Vasbieva \& Kalugina, 2016; Vasbieva et al., 2018). Ethnocentrism as a social phenomenon, one way or another affecting interethnic and intercultural communication, aroused interest in the study of many different foreign and domestic researchers. About ethnocentrism as a phenomenon characteristic of the absolute majority of ethnic groups and peoples, says in his works Ageev (2006), emphasizing both positive and negative aspects. The definition of the term in their works also are offered by Zdravomyslov (2009) and Giddens (1999). Ross and Nisbett (2003) in his work "Man and situation" consider the nature of ethnocentrism from the position of cognitive categorization, as all ethnic groups perceive each other from the position of we and they. However, differences in categorization of we are better, they are worse are known from more ancient times. The domestic researcher Trubetskoy (2003) also reveals the Phenomenon of ethnocentrism in the categorization of friend-foe. The First attempt of classification of ethnocentrism makes Matsumoto (2008), which identifies flexible and rigid ethnocentrism.

An attempt to explain the causes of extreme forms of ethnocentrism is made by social psychologists Adler (1997) and Reich (2006), who concluded that ethnic arrogance and a sense of national superiority, is compensation for the grievances and anger.

Domestic researcher Drobizheva (2003), studying ethnocentric attitudes in modern Russian society and the problems of interethnic relations, pays great attention to the phenomenon of ethnicity. Another Russian scientist - Bromley (1998) considers ethnocentrism as a result of negative transformation of ethnic identity of individuals.

In the framework of cross-cultural social psychology, Lebedeva (2003) actively studied the relationship between ethno-cultural value differences and the degree of negative ethnocentrism. A Study of intragroup reasons for determining ethnocentrism was paid by great attention of the scientists, who allocated the basic components of negative ethnocentrism. Krysko (2003) and Karpenko, Petrovsky and Yaroshevsky (2007) made a significant contribution 
to the study of the issue of discrimination on ethnic grounds. Russian researchers Soldatova (2002) and Ryzhova (2007) in their works use the concept of ethnocentrism as an exclusively negative social phenomenon.

There are also three types of inter-ethnic interaction:

- The influence of one ethnic community on another, in which one ethnic group is active and dominant, and the other inert and passive with respect to this impact. This type of interethnic interaction includes ethnic manipulation, coercion, and so on;

- Ethnic assistance, in which two or more ethnic groups provide assistance and support to each other on an equal footing, show solidarity, achieve unity of intent and jointly seek ways to achieve their goals. This type of inter-ethnic interaction is inter-ethnic cooperation;

- Ethnic opposition, which implies contradictions in positions, disagreement, blocking the efforts of another ethnic group and active promotion of the opposite position up to military action.

- The presented types of interethnic interaction are extreme and have many transitional and intermediate forms. The peculiarities of each type of interethnic interaction are manifested in their result. The result or outcome of long-term inter-ethnic interaction can be:

- Natural or forced assimilation, which manifests itself in different aspects for the two ethnic groups involved in this process: for one of them it is a quantitative increase in the number of its ethnic group, its growth and development, and for the assimilated ethnic group it is the loss of some of its characteristics and features (traditions, customs, values, beliefs, language);

- Ethnic discrimination, which implies a restriction of rights (or even deprivation of these rights) of a certain category of citizens on the basis of ethnicity or national origin;

- Segregation, that is, restriction of rights based on race or ethnicity, resulting in neglect of other peoples, national arrogance and ethnic exclusion (Alisov et al., 2018; Kalugina \& Tarasevich, 2018; Levkovich \& Pankova, 2015; Mamedov, 1996; Petrenko, 2014; Roshchin, 2014; Sorokoumova et al., 2019; Zaslavskaya, 1998).

When building contacts with representatives of other peoples and ethnic groups, most people use as a benchmark and criteria for assessing their own ethnic group with its inherent culture. This type of value judgment is called ethnocentrism. Ethnocentrism is a socio-psychological attitude of perception and evaluation of other cultures and the behavior of their representatives through the prism of their own culture.

\section{MATERIALS AND METHODS}

\section{Method of Research}

The method of interview was used in the research. This method is a universal method that allows analyzing the attitude of students communicating in social networks to intercultural communication and intercultural interaction, and therefore allows solving the following problems:

- To find out how often students are in contact with representatives of other Nations.

- To find out in what area respondents usually intersect with foreign cultural representatives. 
- To find out if communication with other cultures causes discomfort to students.

- To determine whether students prefer representatives of their ethnic group in the formation of any group.

- To find out how often the behavior of foreign cultural representatives seems strange and unacceptable to students.

- To determine how interesting and useful students consider the study of cultural values and customs of other national cultures.

\section{Research Program}

The research program consists of two parts: methodological and procedural. The average length of the interview was 15 to 22 minutes. The students' answers were recorded on tape, as the interview included also open questions, and then they were transcribed and analyzed.

The pilot study revealed that the majority of students (67\%) as a whole often (every day or several times a week) contact in social networks with representatives of other ethnic groups, about a fifth of respondents (19\%) mostly several times a month, while the remaining $14 \%$ in General contact with foreign cultural representatives quite rarely or practically do not contact.

For about a third of the student youth (30\% of respondents) in General, often (or "very often" almost every time a Respondent encounters a representative of another culture, or "quite often" - regularly, but not always) the behavior of foreign cultural representatives seems strange and unacceptable; only $9 \%$ of students very often face unacceptable and strange behavior of representatives of other peoples, about a third (32\%) - quite rarely, noting that they have encountered "practically several times"; another $29 \%$ of students said that they face a similar behavior neither often, nor infrequently.

Based on the data obtained, it can be concluded that the absolute majority of students (68\%) intersect with foreign cultural representatives mainly within the framework of educational activities, $21 \%$ of the total number of respondents contact with representatives of other ethnic groups in the household sphere, only $8 \%$ - in the workplace. About $2 \%$ of students chose the answer other, calling such options as married, married to a representative of another nation.

\section{RESULTS}

The first stage of our research was to find out: "Does communication in social networks with representatives of other cultures and peoples give you discomfort? " About a quarter of the students who took part in the interview, $26 \%$ felt uncomfortable when communicating in social networks with representatives of other cultures. For a little less than half of the respondents ( $47 \%$ of students), it did not matter what culture to communicate with, the remaining $27 \%$ of respondents did not feel any discomfort, moreover, such communication was even interesting to them.

After studying the students' responses regarding the degree of agreement that cross-cultural enrichment may jeopardize the identity of their people, we have the following results: $38 \%$ of students generally agree that the identity of their people may be lost due to cross-cultural enrichment of peoples, one fifth of respondents partially agree with this, partially-no, and about a third of respondents (31\%) generally disagree and believe that cross-cultural enrichment does not affect the preservation of their people's identity. 
The question of preserving the identity of peoples was not so clear, because the answers to the following question "do You Consider the loss of the identity of peoples and the loss of unique traditions and beliefs to be a negative phenomenon? " were very different, depending on the position of the students. After analyzing the students' answers, we divided the students into three groups. In response to this question, many students, conventionally the first group interviewed, who do not consider the loss of identity a negative phenomenon, referred to the process of globalization and its consequences, referring to the loss of identity as a natural process: "Sooner or later, all peoples will lose their identity...", "In the modern world there is a blurring of borders in all spheres, identity in principle becomes unnecessary", "on the Contrary, identity and tradition do not allow people to develop", and so on.

The second group is divided into respondents who advocate the preservation of the identity of peoples and, in particular, of their own people. The preservation of identity, to which respondents refer the national language, traditions, customs, mentality and even national character, is a necessary condition for the preservation of the uniqueness of the entire people and for its development: "Loss of identity - this is definitely bad", "...representatives of all peoples should speak their language, teach the language, to instill in them the traditions and customs that indigenous peoples did not disappear gradually, and is maintained and developed", "If every nation would not seek to preserve their identity and difference from other Nations, we risk to lose all the cultural wealth that is handed down to us by our ancestors..". In addition, the third group consists of those respondents who made arguments both for and against the preservation of identity, but did not indicate their position on this issue.

Despite the fact that for about a third of the respondents, the behavior of foreign cultural representatives in General often seems strange and unacceptable, answering the following question of the interview, which was as follows: "do You Consider it important to know and study the cultural values, traditions and customs of other national cultures?» the majority of students $(61 \%)$ noted that immersion in the culture of other Nations was generally considered important, explaining it by the presence of interest (17\%) and as a need for overall development.

Since one of the objectives of our study was to analyze the representation of supporters of ethnocentrism and cultural relativism among Samara students, it is important to note based on what criteria we attribute a Respondent to supporters of ethnocentric views or to supporters of the concept of cultural relativism.

\section{DISCUSSIONS}

Ethnocentrism in its extreme manifestation, in which we used this term in this work, is a very dangerous social phenomenon that can destabilize the sphere of interethnic influence and intercultural communication. The concept of cultural relativism, presented in this article as a theoretical idea that promotes equality and value of all cultures, denies a universal way of development for all cultures, due to the individual formation and development of each culture, on the contrary, weakens the position of ethnocentrism.

That is why the concept of cultural relativism is so often called a kind of reaction to European ethnocentrism, in which initially European peoples belonged themselves to civilization, and the rest of the world - to the barbarians. Thus, forming the image of a supporter of cultural relativism within the framework of our article, we conclude that it has the following qualities: in General, they often in contact with representatives of other ethnic groups and nationalities; absolutely do not feel discomfort in dealing with foreign cultural representatives, on the contrary, such communication is of great interest; when forming any group/community, they do not give 
Table 1. The answer to the question: "Do you feel discomfort when communicating with foreign cultural representatives in groups?"

\begin{tabular}{lll}
\hline The discomfort when communicating with representatives of other cultures & Boys & Girls \\
\hline Yes, I feel uncomfortable communicating & $12 \%$ & $15 \%$ \\
\hline I do not care what kind of representative I am talking with and which culture he refers to. & $55 \%$ & $47 \%$ \\
\hline No, I do not feel uncomfortable at all. On the contrary, it is even interesting. & $33 \%$ & $38 \%$ \\
\hline
\end{tabular}

preference to representatives of their people, but are guided by other selection criteria; they do not regard the culture of their people as a role model for other Nations; do not agree that the level of development of the pculture of their people is much higher than that of other Nations; they consider it important to interact with representatives of other peoples - even those who are inferior, in their subjective opinion, in the level of development; advocate for the mutual cultural enrichment of peoples, do not see this as a threat to the loss of identity of peoples, including their own people; They consider the culture of all peoples equally important and of equal value; very rarely (almost never) consider the behavior of representatives of other cultures odd or unacceptable; believe that it is important and interesting to study cultural values, immersion in the cultural traditions and customs of other peoples; definitely do not agree that a set of values and traditions accepted in the culture of their people, is efficient and versatile for other peoples.

Thus, after analyzing the interviews of all students, we came to the following conclusions: all respondents were divided into three main groups (supporters of ethnocentrism - about $35 \%$ of respondents, supporters of cultural relativism - $44 \%$ of respondents and respondents who took a neutral position - 21\%).

After analyzing the data presented in Table 1, we came to the conclusion that female respondents are much more likely than male respondents (15\% vs. $12 \%)$ to feel discomfort in communicating with foreign cultural representatives; more than half of the male and female students replied that it did not matter to them which ethnic group to communicate with; accordingly, $33 \%$ of male and $38 \%$ of female students did not feel any discomfort when communicating with representatives of other cultures.

\section{CONCLUSION}

The determinants of interethnic relations is formed in people's ethnic consciousness, which includes the idea of their own ethnic group and other foreign peoples. Often the ethnic identity of people can take hypertrophied forms, for this reason in modern society are often national extremist actions, manifestations of extreme forms of ethnocentrism and xenophobia, disagreement and rejection of other cultural communities.

In this regard, there is a growing need to analyze and study the views and positions of the Samara University youth on the issue of intercultural communication and intercultural interaction in order to form the prerequisites for the successful coexistence of many different cultures within one country.

Criteria that are characteristic of representatives of different ethnic groups with a high level of ethnocentrism: to consider everything that happens in their culture, natural and correct, and in others - wrong; to regard the customs of one's group as universal: what is good for us is good for others; to regard the norms, roles and values of one's group as absolutely correct; to provide comprehensive assistance to the members of one's group if necessary; to be proud of one's 
group; to act in such a way that the representatives of their group feel like winners; to feel hostility towards external groups.

Thus, the proponent of ethnocentrism, according to our study, is a Respondent who: is in General, rarely in contact with representatives of other ethnic groups and nationalities; feels discomfort in dealing with foreign cultural representatives; gives preference to representatives of the ethnos/people at formation of any group/community; considers that culture of its people has to be a role model for all other cultures; agrees that the level of development of culture of its people is much higher, than at other people; does not consider it important to interact with representatives of other peoples who are inferior, in his/her subjective opinion, in the level of development; opposes the cross-cultural enrichment of peoples, because it can jeopardize the identity of his/her people; considers the loss of the identity of its ethnic group clearly a negative phenomenon; does not consider the cultures of all peoples equally important and equal; considers the behavior of foreign cultural representatives in General often strange or unacceptable; sees no need to know and study the cultural values, traditions and customs of other peoples, considering sufficient knowledge of their traditions and customs; agrees that the set of values and traditions adopted in the culture of his/her people, is optimal and universal for other peoples; is a supporter of the policy of multiculturalism and supports the preservation of cultural differences.

The presence of one of the above-mentioned criteria in itself does not mean anything. Only the combination of these criteria and properties (or most of them) in the ethnic consciousness of the individual, allows us to talk about a high level of ethnocentrism.

\section{REFERENCES}

Adler, A. (1997). Understand human nature. St.Petersburg: Publishing house "Academic project".

Ageev, V. S. (2006). Ingroup determinism and its determinant. Intergroup interaction: sociopsychological problems. Moscow: Moscow University press.

Alisov, E. A., Cherdymova, E. I., Trubina, G. F., Yakushev, A. N., Zhdanov, S. P., Popova, O. V., \& Kobzar-Frolova, M. N. (2018). Study of Dominant Type of Student Ecological Focus. Ekoloji 27(106), 357-362.

Artanovsky, S. N. (1979). Problem of ethnocentrism, ethnic identity of cultures and interethnic relations in modern foreign Ethnography and sociology. Actual problems of Ethnography and modern foreign science. Leningrad: Nauka.

Birova, J., Vasbieva, D. G., \& Masalimova, A. R. (2017). Communication in French Foreign Language Learning by Implementing the Aspects of Interculturality. Komunikacie, 19(4), 95-104.

Bromley, Yu. V. (1998). Ethnic processes in modern world. Moscow. Publishing house: Nauka.

Cherdymova, E. I., Faleeva, L. V., Ilkevich, N. G., Sharonov, I. A., Sayfutdinova, G. B., Leusenko, I. V., \& Popova, O. V. (2019a). Socio-Psychological Factors that Contribute to and Impede the Process of Student Eco-Vocational Consciousness Formation. Ekoloji, 28(107), 133140. 
Cherdymova, E. I., Prokopyev, A. I., Karpenkova, N. V., Pravkin, S. A., Ponomareva, N. S., Kanyaeva, O. M., Ryazapova, L. Z., \& Anufriev, A. F. (2019b). EcoArt Therapy as a Factor of Students' Environmental Consciousness Development. Ekoloji 28(107), 687-693.

Drobizheva, L. M. (2001). Ethnicity in modern society. Ethnopolitics and social practices in Russian Federation. World of Russia. Sociology, Ethnology, 10(2), 12-16.

Drobizheva, L. M. (2003). Social problems of interethnic relations in post-Soviet Russia. Moscow: Publishing house of human values Center, St. Petersburg.

Giddens, E. (1999). Sociology. Moscow: Publishing house Editorial of URSS.

Kalugina, O. A., \& Tarasevich, N. A. (2018). Smart technology integration into EFL teaching at the non-linguistic higher school. XLinguae, 11(1XL), 8-18. https://doi.org/10.18355/XL.2018.11.01XL.02

Karpenko, L. A., Petrovsky, A.V., \& Yaroshevsky, M. G. (2007). Short psychological dictionary. Rostov-on-don: "PHOENIX".

Krysko, V. G. (2003). Ethno-psychological dictionary. Moscow: Speech publishing house.

Lebedeva, N. M. (2003). Social psychology of ethnic migration. Moscow: AST.

Levkovich, V. P., \& Pankova, N. G. (2015). Socio-psychological aspects of the problem of ethnic consciousness. Social psychology and social practice. Moscow: Nauka.

Mamedov, N. M. (1996). Culture, ecology, education. Moscow: Publishing house of the state Committee of environmental protection.

Matsumoto, D. (2008). Ethnocentrism, stereotypes and prejudice. St.Petersburg. Primeeuroznak.

Novikova, Y. B., Alipichev, A. Y., Kalugina, O. A., Esmurzaeva, Z. B., \& Grigoryeva, S. G. (2018). Enhancement of socio-cultural and intercultural skills of EFL students by means of culturerelated extra-curricular events. XLinguae, 11(2), 206-217. https://doi.org/10.18355/XL.2018.11.02.16

Petrenko, E. S. (2014). Avanguard of Russian civil society: tomorrow's Russia. Collection of scientific articles of the HSE. Moscow: Academy of professional development and retraining of education workers", pp. 133-139.

Reich, V. (2006). Psychology of the masses and fascism. Moscow: AST.

Roshchin, S. K. (2014). The Problem of ethnocentrism: theory and political reality of the XX century. Races and Nations. (Contemporary ethnic and racial problems), 23, 13-15.

Ross, L., \& Nisbett, R. (2003). Man and situation. The lessons of social psychology. Moscow: Aspect Press.

Ryzhova, S. V. (2007). Personal aspects of nationalism: from negativity to hyperactive identity. Identity and conflict in post-Soviet States. Moscow: Carnegie Moscow center.

Soldatova, G. U. (2002). Strangers among their own: ethnopsychological problems of adaptation of forced migrants. Psychological assistance to migrants: trauma, cultural change, identity crisis. Moscow: Mysl. 
Sorokoumova, E. A., Cherdymova, E. I., Rezvantseva, M. O., Kochneva, L. V., Latysheva, V. V., \& Perkova, E. P. (2019). Environmental and Social Practices of Old Stuff Use and Disposal by Students. Ekoloji, 28(107), 5065-5069.

Trubetskoy, N. S. (2003). History. Culture. Language. Moscow: Publishing house ProgressUniversity.

Ulybina, E. V. (2015). Ethnocentrism as an element of semantic structure of everyday consciousness. Psychological and pedagogical problems of personal development, education and upbringing: Materials of the scientific conference "University science to region". Stavropol, pp. 213.

Vasbieva, D. G., \& Kalugina, O. A. (2016). An Analysis of Students' Intercultural Competence Levels in a Non-Linguistic Higher School. XLinguae, 9(3), 58-69. https://doi.org/10.18355/XL.2016.09.58-69

Vasbieva, D. G., Sokolova, N. L., Masalimova, A. R., Shinkaruk, V. M., \& Kiva-Khamzina, Y. L. (2018). Exploring the EFL teacher's role in a smart learning environment - a review study. XLinguae, 11(2), 265-274. https://doi.org/10.18355/XL.2018.11.02.21

Zaslavskaya, T. I. (1998). Study of mechanisms of social processes. Social trajectory of reforming Russia: Research of the Novosibirsk economic-sociological school. Novosibirsk: Science Publishing House. Sib. enterprise RAS.

Zdravomyslov, A. V. (2009). National consciousness of Russians. Monitoring of public opinion, 2, 161-176.

Correspondence: Roza Sh. Akhmadieva, Doctor of Education, Professor, Rector of Kazan State Institute of Culture, Kazan, Russia. E-mail: roza79.08@mail.ru 